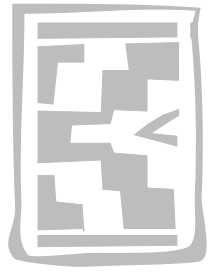

\title{
Evaluation of different adjuvants for foot-and-mouth disease vaccine containing all the SAT serotypes
}

\author{
M. CLOETE ${ }^{1 *}$, B. DUNGU ${ }^{1,2}$, L.I. VAN STADEN ${ }^{1}$, N. ISMAIL-CASSIM ${ }^{1}$ and W. VOSLOO ${ }^{1,3}$
}

\begin{abstract}
CLOETE, M., DUNGU, B., VAN STADEN, L.I., ISMAIL-CASSIM, N. \& VOSLOO, W. 2008. Evaluation of different adjuvants for foot-and-mouth disease vaccine containing all the SAT serotypes. Onderstepoort Journal of Veterinary Research, 75:17-31

Foot-and-mouth disease (FMD) is an economically important disease of cloven-hoofed animals that is primarily controlled by vaccination of susceptible animals and movement restrictions for animals and animal-derived products in South Africa. Vaccination using aluminium hydroxide gel-saponin (AS) adjuvanted vaccines containing the South African Territories (SAT) serotypes has been shown to be effective both in ensuring that disease does not spread from the endemic to the free zone and in controlling outbreaks in the free zone. Various vaccine formulations containing antigens derived from the SAT serotypes were tested in cattle that were challenged 1 year later. Both the AS and ISA $206 \mathrm{~B}$ vaccines adjuvanted with saponin protected cattle against virulent virus challenge. The oilbased ISA 206B-adjuvanted vaccine with and without stimulators was evaluated in a field trial and both elicited antibody responses that lasted for 1 year. Furthermore, the ISA 206 adjuvanted FMD vaccine protected groups of cattle against homologous virus challenge at very low payloads, while pigs vaccinated with an emergency ISA 206B-based FMD vaccine containing the SAT 1 vaccine strains were protected against the heterologous SAT 1 outbreak strain.
\end{abstract}

Keywords: Adjuvant, cattle, control strategies, foot-and-mouth disease, pigs, South Africa, vaccines

\section{INTRODUCTION}

Foot-and-mouth disease (FMD) virus serotypes SAT 1, 2 and 3 are endemic in African buffalo (Syncerus caffer) populations in the Kruger National Park (KNP) and adjoining game farms in the extreme north-eastern corner of South Africa (Vosloo,

* Author to whom correspondence is to be directed. E-mail: cloetemi@arc.agric.za

1 Transboundary Animal Diseases Programme, Onderstepoort Veterinary Institute, Private Bag X05, Onderstepoort, 0110 South Africa

2 Onderstepoort Biological Products, Private Bag X07, Onderstepoort, 0110 South Africa

3 Department of Veterinary Tropical Diseases, University of Pretoria, Pretoria, 0110 South Africa

Accepted for publication 22 October 2007-Editor
Bastos, Sangare, Hargreaves \& Thomson 2002a; Vosloo, Boshoff, Dwarka \& Bastos 2002b). The control zone consists of the endemic game parks and the buffer zone that is divided into a zone with and one without vaccination of cattle (Directorate of Animal Health, Department of Agriculture 2006). The rest of the country has been declared free of FMD without vaccination by the Office International des Epizooties (OIE) in 1996. A total of \pm 55000 cattle are vaccinated against the disease twice annually in the buffer zone where vaccination is practised. In addition, the erection and maintenance of cattle and game-proof fences along all the international borders and western KNP border and adjoining game parks are used as control measures to prevent introduction of FMD through contact between livestock and infected game. The movement of livestock within, into and out of the infected, buffer and 
surveillance zones is controlled by an officially administered permit and identification system. Movement of livestock from the infected and buffer zones to the free zone is not permitted, except for direct slaughter for local consumption at dedicated abattoirs situated in the perimeter of the free zone (Brückner, Vosloo, Cloete, Dungu \& Du Plessis 2004).

The current vaccine used for cattle contains strains of all three SAT serotypes of FMD virus in an aqueous-based vaccine with aluminium hydroxide gelsaponin (AS) as adjuvant. This vaccine has several deficiencies that include the induction of short-lived antibody responses and the consequent need for frequent application of the vaccine (Hunter 1998), and it does not elicit good humoral immunity in pigs (Van Bekkum, Bool \& Vermeulen 1967). The oil-adjuvanted FMD vaccines are suitable for all susceptible species, including pigs. They can also possibly act as slow release vaccines, thus providing longer lasting protection than the aqueous vaccines (Hunter 1998), which means that annual vaccination can be implemented in the FMD control zone of South Africa instead of the current double initial vaccination and 6-monthly boosters required with the aqueous vaccines.

Oil-adjuvanted vaccines have been used successfully in the FMD eradication campaigns in South America (Dora, Coelho Nunes, Goular De Silveira, Jorgens, Rosenberg \& Astudillo 1984; Bahnemann \& Mesquita 1987; Sutmoller, Barteling, Olascoaga \& Sumption 2003). Commercially available single water-in-oil (W/O) adjuvants, Montanide ISA 25 and ISA 50, and double water-in-oil-in-water (W/O/W) adjuvants, ISA 206, without the addition of saponin, elicited protective humoral immune responses against European FMD serotypes in cattle (Barnett, Pullen, Williams \& Doel 1996; lyer, Ghosh, Singh \& Deshmuhk 2001), sheep (Barnett, Keel, Reid, Armstrong, Statham, Voyce, Aggarwal \& Cox 2004; Cox, Barnett, Dani \& Salt 1999; Patil, Bayra, Ramakrishna, Hugar, Misra, Prabhudas \& Natarajan 2002b), goats (Patil, Bayra, Ramakrishna, Hugar, Misra \& Natarajan 2002a) and pigs (Barnett et al. 1996; Barnett, Cox, Aggarwal, Gerber \& McCullough 2002; Barnett \& Carabin 2002). The W/O adjuvants induced faster and better protective immune responses than the W/O/W adjuvants (Barnett et al. 1996; lyer et al. 2001), while the addition of saponin to the W/O FMD vaccine enhanced the antibody titres especially at lower payloads (Smitsaart, Mattion, Filippi, Robiolo, Periolo, La Torre \& Bellinzoni 2000). The addition of saponin to ISA 206 adjuvanted FMD vaccines containing $\mathrm{O} 1 \mathrm{Campos}$ enhanced the specific antibody responses in cattle and pigs (Smitsaart, Esponoza, Sanguinetti, Fillipi, Ham \& Bellinzoni 2004). Oilbased FMD vaccines containing antigens from the International Vaccine Bank, Pirbright were shown to be more stable at $+4^{\circ} \mathrm{C}$ than the AS vaccine formulations (Barnett \& Doel 1992; Barnett et al. 1996). Barnett \& Statham (2002) developed a novel approach for the formulation and storage of oil vaccines that involves the layering of the individual components of FMD vaccine in the same primary container and then storing the product at ultra-low temperatures. The advantage is that the shelf life can be substantially extended.

Another advantage of oil adjuvanted FMD vaccines is that they can provide early protection against infection. ISA 206 adjuvanted FMD vaccines containing the $\mathrm{O}, \mathrm{A}, \mathrm{C}$ and Asia $1 \mathrm{FMD}$ serotypes without saponin and given as a once-off vaccination protected cattle (Barnett et al. 1996; lyer et al. 2001; Cox, Voyce, Parida, Reid, Hamblin, Paton \& Barnett 2005; Cox, Voyce, Parida, Reid, Hamblin, Hutchings, Paton \& Barnett 2006), sheep (Cox et al. 1999), goats (Barnett et al. 2002; Patil et al. 2002a) and pigs (Barnett et al. 1996; Barnett et al. 2002; Barnett \& Carabin 2002) within 4-7 days post vaccination (pv). Cattle were protected against direct contact challenge following emergency vaccination (Cox et al. 2005), and an increase in payload reduced subclinical infection, leading to fewer persistently infected animals (Cox et al. 2006). Cattle vaccinated with a commercial ISA 206 adjuvanted monovalent 01 Manisa vaccine (Merial, Pirbright UK, $3 \mathrm{PD}_{50}$ ) were partially protected 4 days $\mathrm{pv}$, and fully protected 7 days pv after virulent virus challenge (Golde, Pacheco, Duque, Doel, Penfold, Ferman, Gregg \& Rodriquez 2005).

The performance of selected oil adjuvants containing the SAT serotypes of FMD virus has been investigated previously (Hunter 1996). Preliminary trials with oil-adjuvanted vaccines without saponin containing SAT strains showed that W/O/W- and W/Oadjuvanted vaccines elicited higher antibody responses than the AS vaccines (Hunter 1996), and should therefore be able to protect for longer time periods than the AS vaccines.

The aims of this investigation were to evaluate different oil-adjuvanted FMD vaccine formulations to determine which formulation would protect cattle from homologous virulent virus challenge, to perform a field evaluation of the oil-adjuvanted FMD vaccine intended to replace the current aqueous vaccine used in areas surrounding the KNP where FMD vaccination is practised, to determine whether 
the addition of saponin to the W/O/W emulsion will positively affect the vaccine as previously demonstrated (Smitsaart et al. 2004), and finally, to determine the level of protection induced by oil-based vaccines using lower payloads as well as their efficacy in pigs using the SAT strains.

\section{MATERIALS AND METHODS}

\section{Preparation of different vaccine formulations}

Table 1 summarises the composition of FMD vaccine formulations and their intended use in this study. Vaccines were formulated according to the manufacturers' instructions.

\section{Animal trials to determine the efficacy of the various vaccines}

\section{Evaluation of different oil-adjuvanted vaccine formulations}

Four groups of six FMD-free cattle were vaccinated with FMD vaccine formulations 1-4 (Table 1). Animals vaccinated with vaccine formulation 1 were given booster vaccinations after 4 weeks, while animals receiving vaccine formulations $2-4$ were boosted after 8 weeks. Samples were collected at 4 -week intervals for 40 weeks after vaccination for serological testing.

The two groups vaccinated with the vaccine formulations 1 and 2 were challenged 50 weeks pv and those vaccinated with vaccine formulations 3 and 4 at 56 weeks pv with SAT 2B. One control animal was included in each of the challenge tests. They were brought into the containment facilities at the Transboundary Animal Diseases Programme (TADP), and challenged with $10^{4}$ tissue culture infectious doses $\left(\mathrm{TCID}_{50}\right)$ tissue culture adapted SAT 2B strain administered intradermally into the tongue (Kitching, Barnett \& Donaldson 2000; Stellmann, Terr, Favre, Brun \& Fontaine 1977). The animals were monitored for clinical signs of FMD and their temperatures recorded daily for 10 days. Sera were collected before challenge and 10 and 18 days after challenge for antibody titre determination. Animals were considered protected from live virus challenge when they did not show any FMD-like lesions on any of their four feet.

\section{Safety testing of ISA 206B-based FMD vaccine}

Three FMD-free cattle were inoculated intradermally into the tongue at ten points using $0.1 \mathrm{ml}$ of the
FMD vaccine formulation 5 containing monovalent SAT 2B antigen and saponin. On Day 4 the cattle were injected with $3 \mathrm{~m} \ell$ vaccine subcutaneously in the neck. The animals were monitored for a further 6 days. The vaccine was considered safe if no FMD lesions were observed on the tongue and feet, and if there was no swelling at the site of injection.

\section{Potency test of ISA 206B-based FMD vaccines with decreased payload}

Two groups of five FMD-free cattle were vaccinated with a 0.25 dose $(0.5 \mathrm{ml}$ instead of $2.0 \mathrm{ml})$ of either monovalent formulation 5 or pentavalent FMD vaccine formulation 6 (Table 1). Sera were collected on Days $0,7,14,21$ and 31 for testing for antibodies. The cattle vaccinated with the monovalent SAT 2 vaccine 5 and two unvaccinated controls, free from FMD, were challenged 21 days pv with $10^{5} \mathrm{TCID}_{50}$ of live SAT 2B. The cattle vaccinated with pentavalent vaccine 6 , and two unvaccinated controls were challenged with $10^{5}$ cattle infectious doses of SAT 3 strain. The animals were monitored for clinical signs of FMD and their temperatures recorded daily for 10 days. They were considered protected from live virus challenge when they did not show any FMD-like lesions on any of their feet, while the vaccine was deemed protective if three or more animals were protected from clinical FMD.

\section{Potency test of ISA 206B-based FMD vaccine following emergency vaccination}

In November 2000 an FMD outbreak caused by SAT 1 occurred in a cattle feedlot in South Africa (Brückner, Vosloo, Du Plessis, Kloeck, Connoway, Ekron, Weaver, Dickason, Schreuder, Marais \& Mogajane 2002). A pig breeding facility was also located on the premises and approximately 50000 pigs were vaccinated with emergency FMD vaccine formulation 7 (Table 1) (Brückner et al. 2002). Five vaccinated pigs were brought to the containment facilities at TAPD 36 days pv. The five pigs as well as two unvaccinated controls, free from FMD, were challenged with $10^{5.3} \mathrm{TCID}_{50}$ per $0.1 \mathrm{ml}$ (pig kidney titrated) SAT 1 outbreak strain (SWL 3/00/1) using $0.1 \mathrm{ml}$ per site, intradermally into each of the two digits of the heel bulb of one foot (De Leeuw, Tiessink \& Van Bekkum 1979). The animals were monitored for clinical signs of FMD and their temperatures recorded daily for 10 days. Animals were considered protected from live virus challenge when they did not show any FMD-like lesions on any of their feet or in their mouths (De Leeuw et al. 1979), excluding the infected and adjacent claw. The vac- 


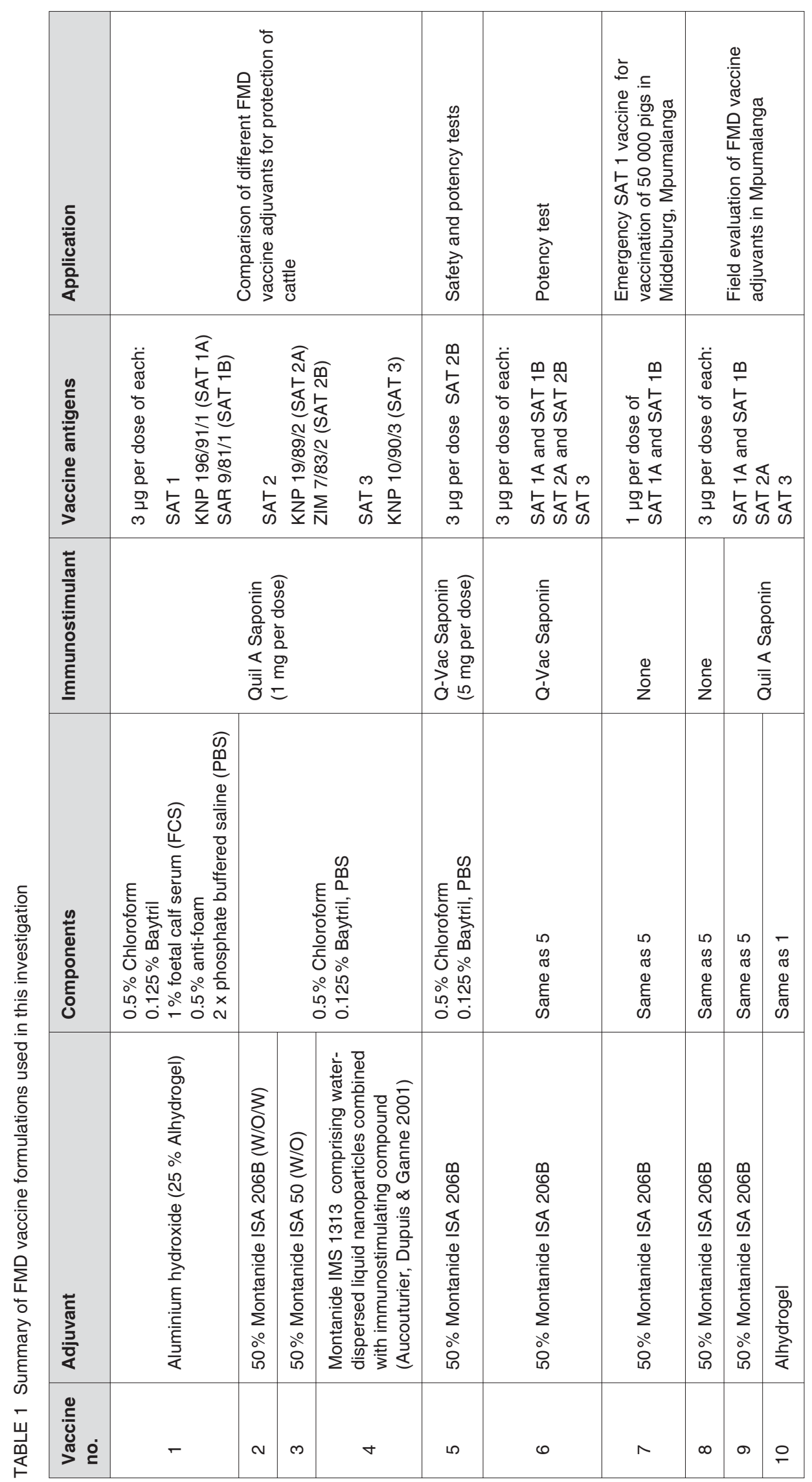


cine was deemed protective if three or more animals were protected from clinical FMD.

\section{Field evaluation of different oil-based vaccine formulation}

Vaccine formulations 8-10 (Table 1) were evaluated in cattle at two dip tanks named Daantjie and Msogwaba, respectively, in the White River district, located in the buffer zone where cattle are vaccinated. Unvaccinated calves were used in the study and were bled, tagged and information logged. At both dip tanks, two groups of 50 calves each were vaccinated with vaccine formulations 8 and 9 . The third group vaccinated with vaccine formulation 10 consisted of 47 calves at Daantjie and 33 at Msogwaba. Sera were collected 1, 2, 4, 12, 25 and 55 weeks pv at Daantjie and 1, 3, 22, 55 and 82 weeks pv at Msogwaba. The cattle vaccinated with the vaccine formulation 10 were boosted 4 and 24 weeks pv, while cattle vaccinated with vaccine formulations 8 and 9 were boosted at 12 weeks pv. All the groups of cattle at Msogwaba were re-vaccinated at Week 55.

\section{Serological testing}

All sera were tested for antibodies to SAT 1, SAT 2 and SAT 3 using the liquid phase blocking ELISA (LPBE) (Hamblin, Barnett \& Hedger 1986) with virus homologous to the vaccine strains (SAT 1: SAR9/81/1, SAT 2: ZIM7/83/2 and SAT 3: KNP10/90/3). Virus neutralization tests (VNT) were performed as described by Rweyemamu, Booth, Head \& Pay (1978), using the homologous virus to each of the five vaccine strains. The neutralizing antibody titre of the serum was expressed as the reciprocal of the dilution that neutralizes $50 \%$ of the virus. The values were represented as geometric mean titre expressed in $\log _{10}$ (Patil et al. 2002a). For both tests a cut-off of $>1.6 \log _{10}$ was taken as seroconversion to a serotype of FMD virus. Statistical analyses were performed using Genstat $₫$ for Windows $₫$ ( $7^{\text {th }}$ edition) at a $1 \%$ confidence level (Payne 2003).

\section{RESULTS}

\section{Evaluation of the ability of different oil- adjuvanted FMD vaccines to protect cattle from virulent virus challenge}

FMD vaccine formulations 1-4 (Table 1) were tested in four groups of six cattle. They were vaccinated and boosted, sera were collected at 4-weekly intervals and the neutralizing antibody titres determined. The average VNT titres for the six animals vacci- nated with the different vaccine formulations at each time point is shown for SAT 1 (Fig. 1A and B), SAT 2 (Fig. 1C and D) and SAT 3 (Fig.1 E). For all the five SAT antigens included in formulations $1-4$, the ISA 206B (formulation 2) and ISA 50 (formulation 3) vaccines induced higher average antibody titres in animals that received a booster vaccination at Week 8 , as well as longer lasting immune responses, than for formulations 1 (AS) and 4 (IMS 313) (Fig. 1A-E). The antibody titres elicited by the ISA 206B (formulation 2) and ISA 50 (3) formulations showed a steady decline over time from 12 weeks pv and, in general, were still positive at Weeks 32-40 (Fig. $1 \mathrm{~A}-\mathrm{E})$, while the antibody titres for the SAT $2 \mathrm{~B}$ antigen remained positive for the duration of the trial (Fig. 1D). There was no statistical difference between the average antibody titres of formulations 2 and 3 (Fig. 1A-E). The average immune response elicited by the antigens present in the AS vaccine (formulation 1) had largely disappeared by Week 12 (Fig. 1A-C), except for the SAT 2B (Fig. 1D) and SAT 3 antigens (Fig. 1E), where neutralizing antibodies could be demonstrated until Week 24. Only SAT 3 (Fig. 1E) elicited an increase in average antibody titres following the booster vaccination at Week 4 with the AS vaccine. The initial antibody responses to the IMS1313 vaccine (formulation 4) were low for all the antigens and were of short duration (most average figures were below the cut-off level at Weeks 20-28) (Fig. 1A-E), with animals only seroconverting to the SAT $2 \mathrm{~A}$ antigen after receiving the booster vaccination at Week 8 (Fig. 1C). In contrast, the SAT 1B antigen induced an average titre of $2.2 \log _{10}$ at Week 3 (Fig. 1B).

\section{Challenge with virulent FMD SAT 2B strain}

Vaccine formulations 1 and 2 protected four of six cattle each. The control animal succumbed to clinical disease. Of the animals that were vaccinated with vaccine formulation 3 , one was protected after challenge, while none of the cattle vaccinated with vaccine formulation 4 were protected. The control animal did not develop clinical disease, indicating a technical problem with the infection of that particular animal, but the fact that most of the vaccinated animals were diseased indicated that the virus was viable and that the challenge was successful. All the groups of cattle developed high levels of neutralizing antibodies against SAT 2A (Fig. 1C) and SAT 2B (Fig. 1D) following challenge with this serotype, while cross reaction with the other serotypes was also observed (Fig. $1 \mathrm{~A}-\mathrm{E}$ ). Such cross-reactions have been observed during active infection (Cottral 1972a, b). 

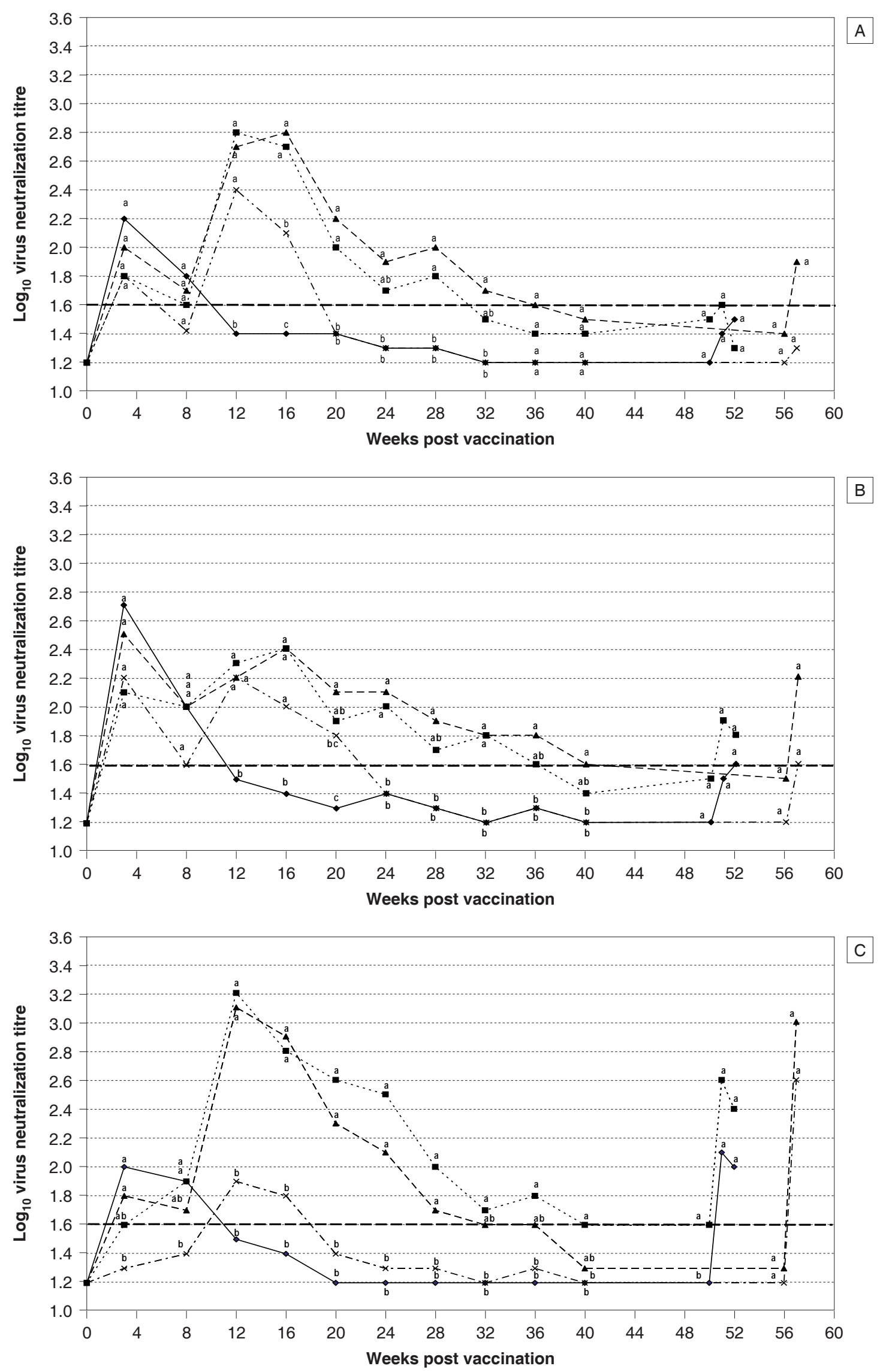

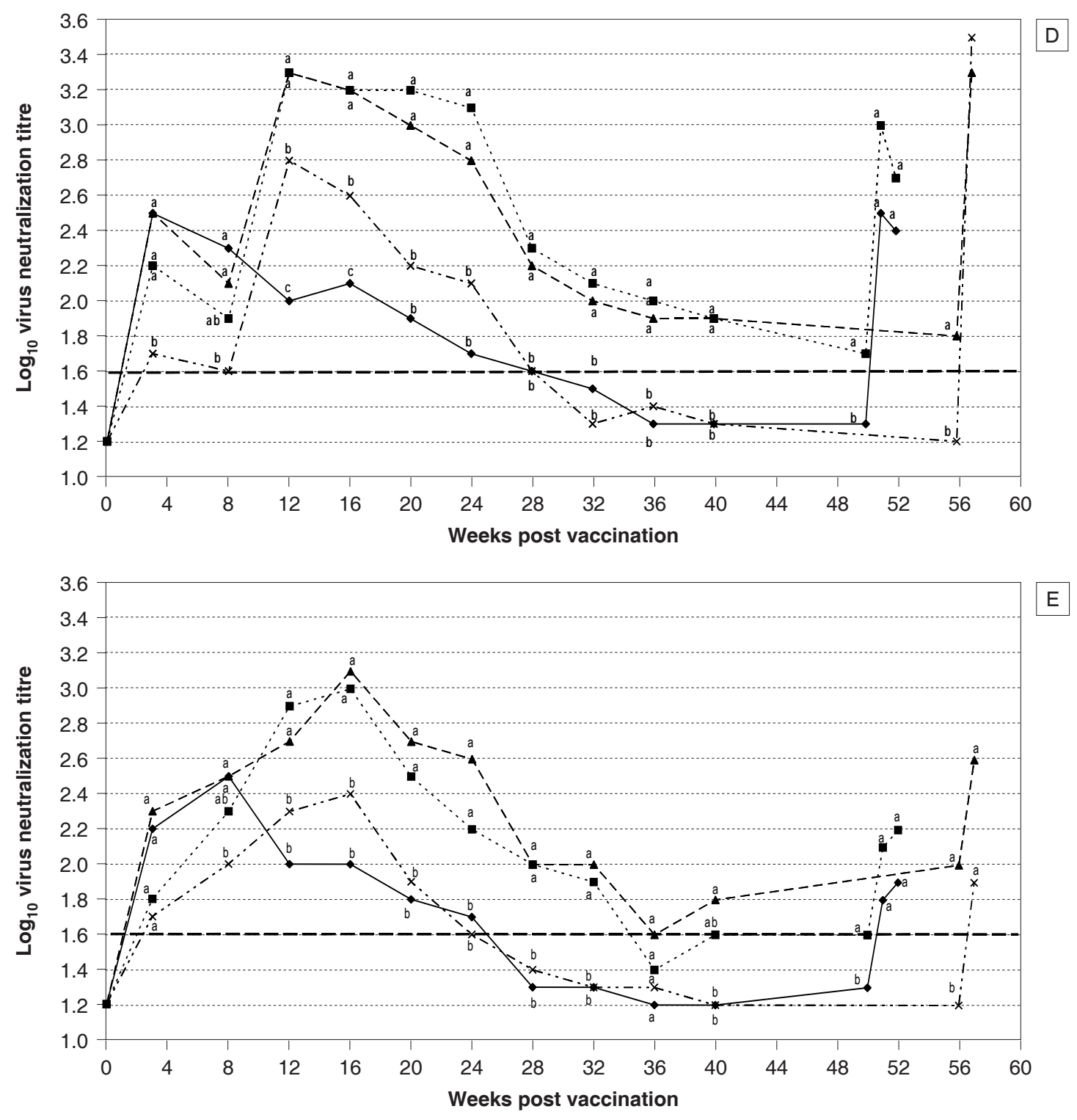

$\longrightarrow$ Formulation $1 \quad \cdots-$ Formulation $2 \quad-\star-$ Formulation $3 \quad--x-$ Formulation 4

FIG. 1 Evaluation of FMD vaccine formulations 1-4

Cattle vaccinated with formulation 1 received a booster at 4 weeks, while all other groups received boosters at 8 weeks. Neutralizing titres were determined using VNT and titres $\geq 1 / 45$ or $\geq 1.6 \log _{10}$ are deemed positive (the cut-off is shown). The neutralizing titres elicited by the different SAT antigens present in the different vaccine formulations for weeks 4-40 were analysed using a one-sided ANOVA to test for differences in immune responses between the different vaccine formulations. The data were acceptably normal and variances were homogenous at the $1 \%$ confidence level. The neutralizing titres determined at weeks 50-59 were analysed differently via analysis of an unbalanced design using Genstat regression to test for differences in immune responses between the different vaccine formulations. The data were acceptably normal with heterogeneous treatment variances. The treatment means were separated using Fishers' protected t-test least significant difference (LSD) at the $1 \%$ level of significance (Snedecor \& Cochran 1980). The points on the graph represent the average titres of the six cattle in each group per collection date. Titres to SAT 1A (A), SAT 1B (B), SAT 2A (C) and SAT 2B (D) and SAT $3(E)$ are indicated in separate graphs.

If the probability for difference was $<0.01$, the statistically significant differences between the groups vaccinated with different vaccine formulations at each time point are denoted by different letters, and when the probability was $>0.01$, it indicated no differences in immune response and are denoted by the same letter. 

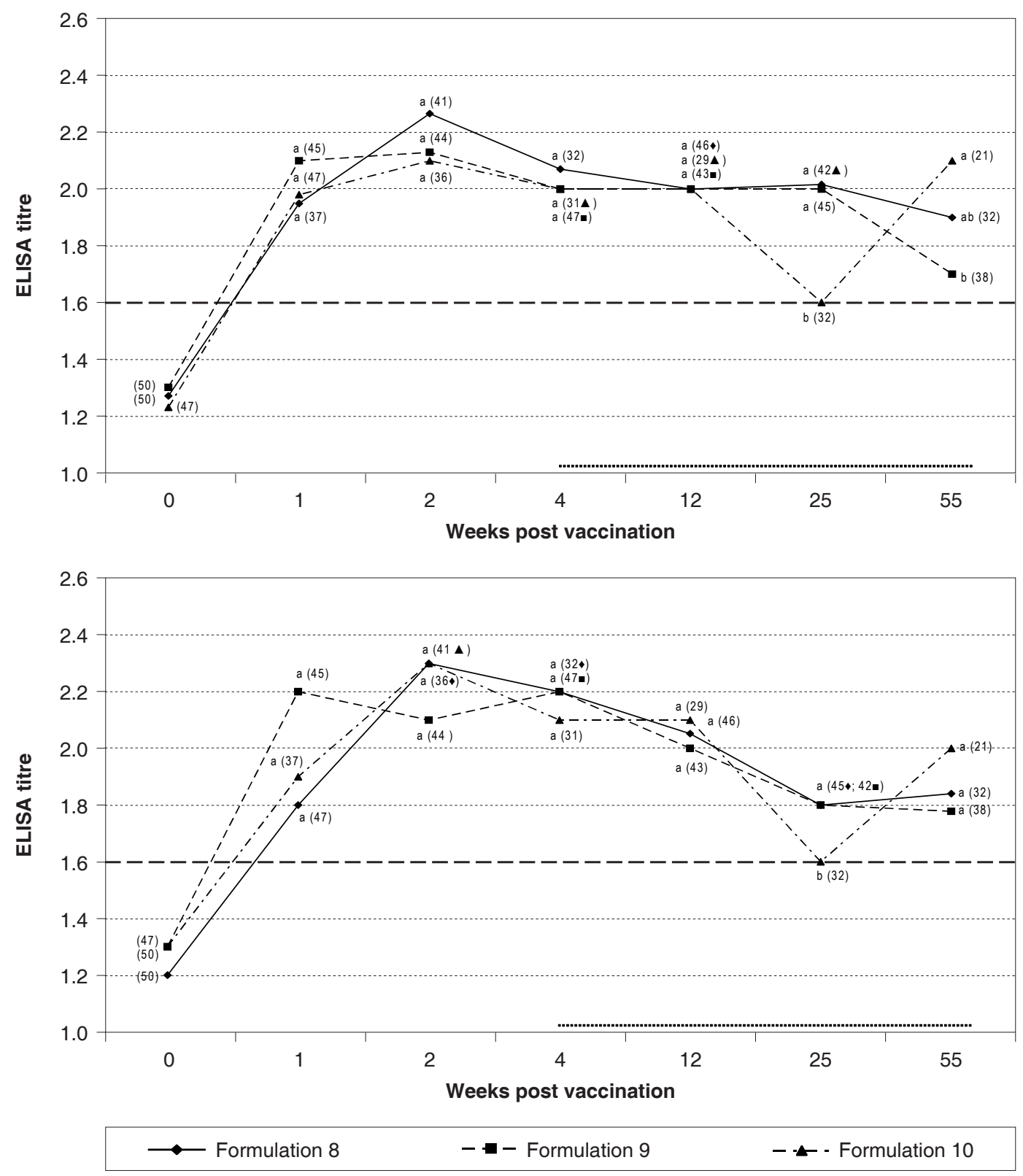

FIG. 2 Evaluation of FMD vaccine formulations 8, 9 and 10 at two dip tanks

The animals vaccinated with vaccine formulation 10 were revaccinated at 4 and 24 weeks while all those that received vaccine formulations 8 and 9 were revaccinated at 12 weeks. All three groups received booster vaccinations at 55 weeks at Msogwaba dip tank.

The graphs represent the average titres against the different vaccine formulations as determined using a LPB-ELISA, and $\geq 1.6 \log _{10}$ was taken as positive. The data were analyzed using an unbalanced design as described in the legend of Fig 1. Average titres to SAT 1 (A), SAT 2 (B), and SAT 3 (C) FMD vaccines strains at Daantjie and SAT 1 (D), SAT 2 (E) and SAT 3 (F) at Msogwaba dip tanks are indicated in separate graphs. The numbers of sera collected and analysed at each time point are indicated in brackets.

If the probability for difference was $<0.01$, the statistically significant differences between the groups vaccinated with different vaccine formulations at each time point are denoted by different letters, and when the probability was $>0.01$, there were no differences in immune response and are denoted by the same letter. The dotted line at the bottom of the graphs from week 4 represents extended intervals between sampling periods. 

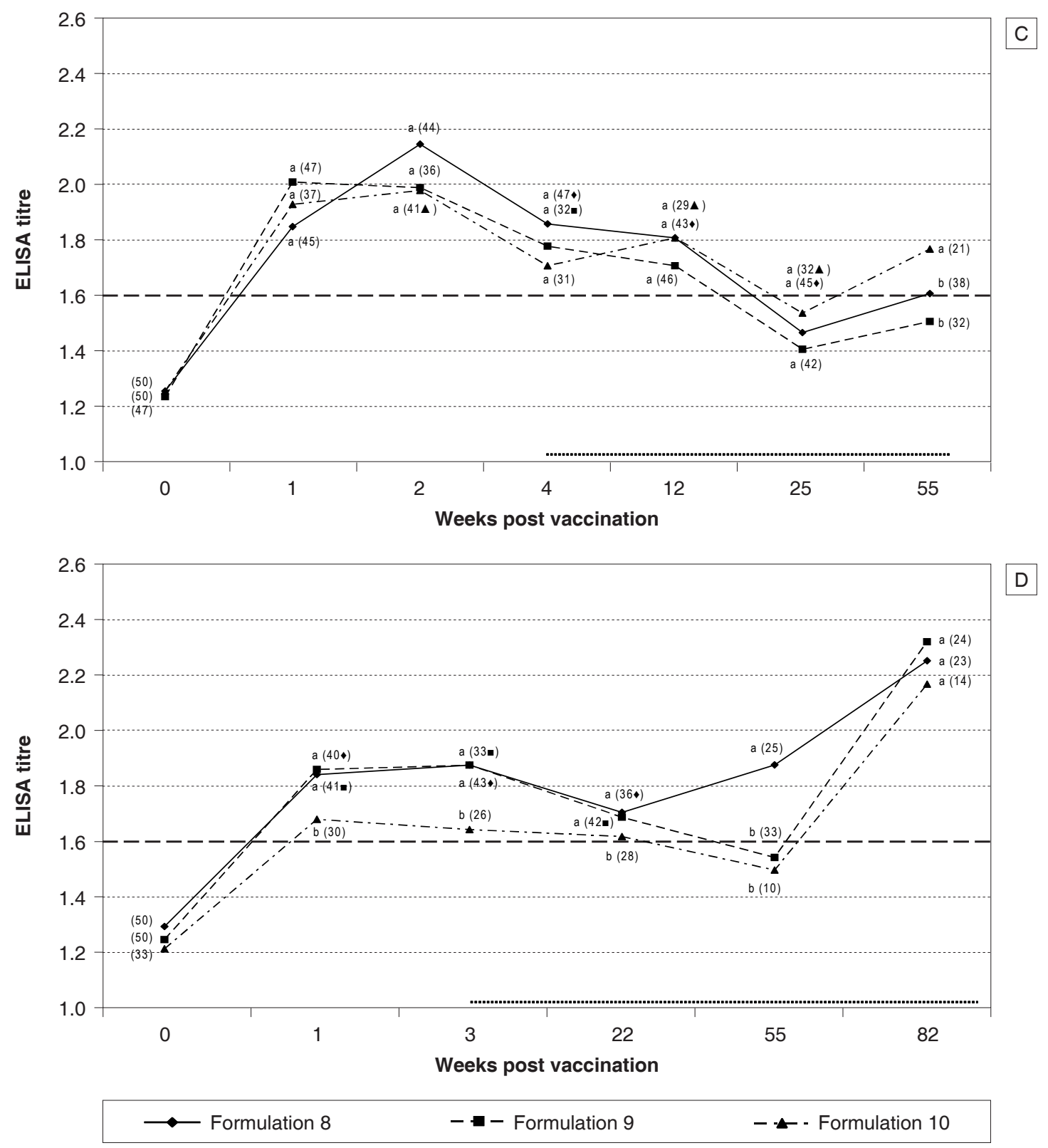

FIG. 2 (cont.)

\section{Safety testing and potency testing of ISA 206B- adjuvanted $F M D$ vaccines with reduced payloads}

Formulation 5 did not cause any adverse reactions at the sites of injection, indicating that the adjuvant/ antigen combination is safe for use. Similarly, no adverse reactions were reported in the study using formulations 1-4 or in the large scale field evaluation for vaccines 8-10 in the White River area.

The protective efficacy of the ISA 206B-adjuvanted FMD vaccines was also tested using decreased payloads of antigen. In the first potency test five cattle were vaccinated with a 0.25 dose of vaccine for- mulation 5. After they and two control cattle were challenged with $10^{5} \mathrm{TCID}_{50}$ of SAT 2A virus, four of the five vaccinated cattle were protected. Both control animals developed lesions on all four feet.

Cattle vaccinated with a 0.25 dose of vaccine formulation 6 developed neutralizing antibodies against the SAT 1 and 2 antigens in the vaccine by Day 14, but not against SAT 3 (results not shown). After they and two unvaccinated controls were challenged with SAT 3 strain, four of the five vaccinated cattle were protected, while the fifth animal developed FMD lesions on only one of its feet. Both the control animals developed lesions on all four feet. 

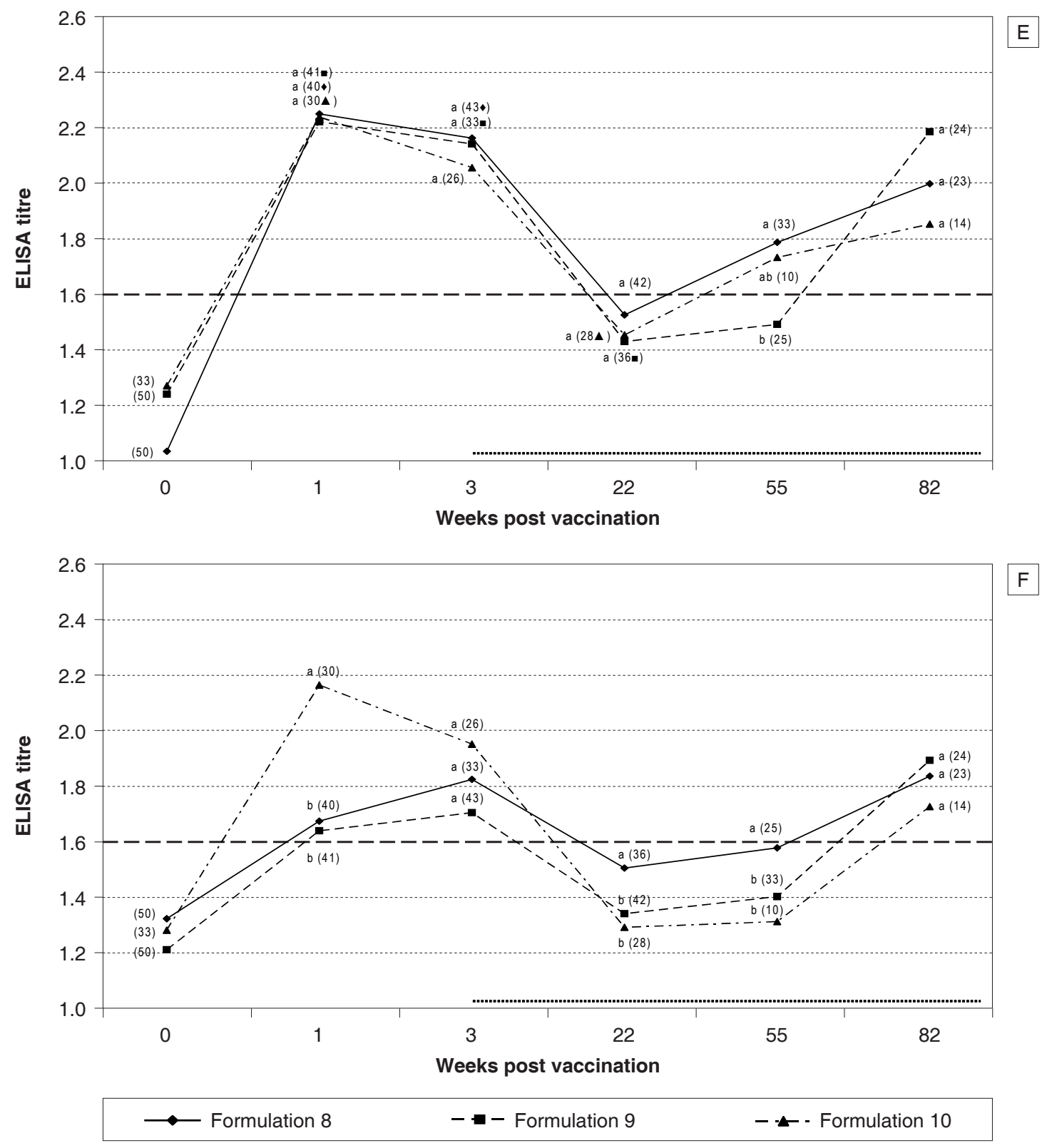

FIG. 2 (cont.)

\section{Challenge of pigs with heterologous virus following emergency vaccination with an ISA 206B-adjuvanted SAT 1 FMD vaccine}

All the vaccinated pigs were protected while both control animals developed lesions in their mouths and on all four feet.

\section{Field evaluation of ISA 206-based trivalent FMD vaccine}

The different FMD vaccine formulations were subsequently tested in the field and compared to the standard AS vaccine to allow for larger numbers of animals and to investigate the efficacy of all the formulations. Groups of animals were vaccinated with formulations 8-10 at the two different dip tanks, sera collected on a regular basis and antibodies to all three serotypes determined using the LPBE. The numbers varied per collection date as some animals were sold, died or the farmers did not arrive at the dip tank with the animals.

The results for the Daantjie (Fig. $2 \mathrm{~A}-\mathrm{C}$ ) and Msogwaba (Fig. 2D-F) dip tanks are presented separately. At Daantjie vaccine 9 (ISA 206B with saponin) induced a marginally better response to all the antigens at Week 1 , indicating that the addition of 
an immunostimulant to the oil-based vaccine could quicken the immune response, but by Week 2 formulation 8, containing ISA 206B without saponin, induced somewhat higher titres, although none of these values were statistically different (Fig. $2 A-C$ ). The titres elicited by all the antigens in all the vaccine formulations declined from Week 3 and by Week 25 the average titre for formulation 10, the AS vaccine, was negative (Fig. $2 A-C$ ). There were no positive titres to the SAT 3 antigen present in the oil formulations from Week 25 (Fig. 2C). The titres induced by the SAT 1 and 2 antigens in the oil formulations remained positive until Week 55 (Fig. 2A and $B)$. The group of cattle vaccinated with formulation 10 , the AS vaccine, and given a booster vaccination at Week 24, had positive titres against all three antigens at Week 55 (Fig. 2A-C).

The immune responses at the Msogwaba dip tank (Fig. 2D-F) were more variable, with little difference between the formulations when measuring antibody titres to SAT 2 (Fig. 2E), while the two ISA 206B formulations (8 and 9 ) induced similar responses to SAT 1 , which were significantly higher than the response induced by the AS vaccine (formulation 10) (Fig. 2D). Only vaccine 10 induced high levels of antibodies to SAT $3\left( \pm 2.2 \log _{10}\right)$ at Week 1 , but these declined to a similar level to the antibodies elicited by formulations 8 and $9\left(1.7 \log _{10}-1.9 \log _{10}\right)$ at Week 3 (Fig. 2F). At Week 22 only antibodies to SAT 1 (Fig. 2D) could be detected in all 3 formulations, while no titres to SAT 2 (Fig. 2E) and SAT 3 (Fig. 2F) could be demonstrated. The cattle vaccinated with formulation 10 received a booster vaccination at Week 24, resulting in a positive titre against the SAT 2 antigen at Week 55 (Fig. 2E), but not against the SAT 1 antigen (Fig. 2D). At Week 55 the antibody titres against the SAT 1 and 2 antigens in formulation 8 were positive (Fig. 2D and E) while no antibodies were induced by the SAT 3 antigen in all three vaccine formulations (Fig. 2F). The booster vaccinations at Week 55 in all the groups of cattle resulted in positive titres to all three antigens in all the formulations at Week 82 (Fig. 2D-F).

\section{DISCUSSION}

It is imperative that research should be intensified to develop more effective vaccines containing the SAT serotypes and to investigate the use of different adjuvants and other boosters that could elicit longer lasting immunity, as gathering animals at frequent intervals for vaccination in extensive farming systems can create logistical problems.
The FMD ISA 206B (formulation 2) and ISA 50 (formulation 3) containing antigens from the three SAT serotypes and containing saponin as immunostimulant elicited higher and longer lasting VNT antibody titres in cattle than the AS (formulation 1) and IMS 1313 (formulation 4) vaccines. In the group of cattle vaccinated with FMD vaccine adjuvanted with ISA 206B and containing saponin, a booster vaccination after 8 weeks did not elicit initial high antibody responses, but titres above the $1.6 \log _{10}$ cut-off titre were maintained for $28-50$ weeks. The cattle vaccinated with the AS FMD vaccine that received a booster vaccination at 4 weeks only maintained antibody titres above the cut-off titre for 8-12 weeks. Hunter (1996) reported similar findings in a preliminary evaluation of oil-adjuvanted FMD vaccines containing the SAT serotypes. Cattle vaccinated with a monovalent SAT 1 vaccine containing different oil adjuvants (W/O, W/O/W and incomplete Freund's) without saponin as immunostimulant, maintained VNT titres higher than $2.2 \log _{10}$ for at least 6 months, whereas the cattle vaccinated with the AS vaccine only maintained the VNT titres above the cut-off of $1.6 \log _{10}$ for 2-3 months (Hunter 1996), which corresponded with our findings. Groups of cattle vaccinated with $\mathrm{W} / \mathrm{O} / \mathrm{W}$-adjuvanted $\mathrm{FMD}$ vaccine containing the same SAT 1-3 vaccine strains described in this investigation developed neutralizing antibody responses of at least $2.2 \log _{10}$ within 7 days and maintained antibody levels of above the cut-off of $1.6 \log _{10}$ for the duration of the trial, which was up to 330 days (Hunter 1996). The difference in initial immune responses between the two studies could possibly be ascribed to the payload of antigen present in the vaccine formulations, since Hunter (1996) used a payload of $12 \mu \mathrm{g}$ of each antigen per dose, whereas the cattle in this trial were vaccinated with $3 \mu \mathrm{g}$ of each antigen per dose.

In this investigation four out of six of the cattle vaccinated with the AS and ISA 206B-adjuvanted FMD vaccines were protected against live FMD virus challenge 50 weeks pv despite the fact that no neutralizing antibodies could be detected in the first group. In a follow-up potency test with an ISA 206Badjuvanted FMD vaccine (formulation 5) containing SAT 1-3 with added saponin as immunostimulant, cattle were protected against SAT 3 challenge using a payload of $0.75 \mu \mathrm{g}$ of FMD SAT antigen per dose, even though the cattle did not seroconvert to SAT 3 before challenge. Similarly, $0.75 \mu \mathrm{g}$ per dose of SAT 2B in an ISA 206B adjuvant containing saponin (formulation 6) was sufficient to protect cattle from homologous live virus challenge. Only one of the six cattle vaccinated with the ISA 50 (formula- 
tion 3) vaccine was protected from live virus challenge, despite the presence of neutralizing antibodies to the SAT 2B antigen at the time of challenge. These results show that a high neutralizing antibody response does not necessarily lead to protection and that cattle with a negative antibody titre can still be protected against homologous virus challenge. The cattle might succumb to heterologous challenge, but this has not been tested. In a previous challenge experiment only $3 / 4$ and $2 / 5$ cattle vaccinated but not boosted with a W/O/W-adjuvanted vaccine without saponin containing SAT 1-3 antigens were protected when challenged 7 and 11 months after vaccination, respectively, although they received a much higher payload of antigen, and still had detectable antibody titres (Hunter 1996). Therefore, it seems that the booster vaccination and the addition of saponin may have had an effect on the protection levels of the vaccinated animals in our study.

The cattle vaccinated with the AS FMD vaccine (formulation 1) were probably protected by cellular immunity caused by the presence of saponin, since it induces strong $\mathrm{TH} 1$ and $\mathrm{TH} 2$ responses and moderate CTL responses to some proteins, probably as a result of forming mixed protein-saponin micelles (Cox \& Coulter 1997). Barnett and co-workers (2004) demonstrated that sheep vaccinated with AS vaccine containing $\mathrm{O} 1$ Lausanne elicited both neutralizing antibody and gamma interferon responses. $\mathrm{CD}^{+}$response in cattle following infection with FMD similarly showed that cellular responses might be involved during FMD infection (Childerstone, CedilloBaron, Foster-Cuevas \& Parkhouse 1999). Pigs vaccinated with a $1 \mu \mathrm{g}$ per dose of emergency SAT 1 FMD vaccine formulation 6 without saponin were fully protected from heterologous virus challenge. Phylogenetic comparisons indicated that the outbreak virus clustered in the same topotype as the vaccine strains (Brückner et al. 2002), while cross neutralization tests indicated a close antigenic relationship to the SAT 1 vaccine strains ( $r$-value of 0.6 ) (J.J. Esterhuysen, personal communication 2001). These results demonstrate that ISA 206B-adjuvanted FMD vaccine without saponin can protect pigs against live heterologous virus challenge 36 days $\mathrm{pv}$ if the challenge strain is antigenically and genetically closely related to the vaccine strains. In a recent study, pigs vaccinated with a W/O/W FMD vaccine at a payload of $3 \mu \mathrm{g}$ per dose all developed FMD signs when challenged with homologous live virus 7 days pv, whereas pigs vaccinated with an increased payload of $12 \mu \mathrm{g}$ per dose were partially protected when challenged at 7 days pv, and completely protected when challenged 14 days pv (Eblé,
Bouma, De Bruin, Van Hemert-Kluitenberg, Van Oirschot \& Dekker 2004) These pigs developed weak IgA responses following vaccination that increased significantly after challenge on Day $7 \mathrm{pv}$. However, protection was correlated with the neutralizing antibody response and not the IgA responses ((Eblé, Bouma, Weerdmeester, Stegeman \& Dekker 2007). An FMD vaccine containing O1 Manisa $(3 \mu \mathrm{g} / \mathrm{ml})$ and adjuvanted with $\mathrm{W} / \mathrm{O} / \mathrm{W}$ emulsion protected pigs from heterologous virus challenge $(O$ Taiwan), although the challenge strain was not genetically or antigenically ( $r$-value of 0.4 ) closely related (Eblé, De Bruin, Bouma, Van Hemert-Kluitenberg \& Dekker 2006).

The Montanide $₫$ IMS 1313 adjuvant (FMD vaccine formulation 4) consisting of nanoparticles containing an immunostimulant in a water-based formulation was also evaluated in this investigation. Cattle vaccinated with vaccine formulation 4 containing saponin as immunostimulant that received a booster vaccination at 8 weeks were not protected from live virus challenge 1 year after vaccination. The IMS 1313 adjuvant containing saponin did not show any auto-boost effects, even though nanoparticles can act as slow-release vaccines (Cox \& Coulter 1997). Preliminary results of the evaluation of microsphere-encapsulated FMD vaccine containing the SAT 1-3 serotypes as slow-release vaccines also showed disappointing results (unpublished data 2005). IMS-adjuvanted FMD vaccines presented contrasting results in mice in which they elicited similar or higher antibody titres than the ISA 206-adjuvanted FMD vaccine (Quattrocchi, Fondevila, Pappalardo, Sadira \& Zamorano 2006), while also inducing interleukin 2 (IL-2), IL-4 and gamma interferon responses and protecting mice at 7 days pv (Quattrocchi, Bianco, Fondevila, Pappalardo, Sadira \& Zamorano 2004).

The field evaluation of the ISA 206B-adjuvanted FMD vaccine in the presence or absence of saponin as immunostimulant yielded different results at Daantjie and Msogwaba dip tanks even though the same vaccine formulations were used at both dip tanks. This demonstrates clearly the influence of the vaccination campaign at different localities where it is possible that vaccines were not applied in an optimal manner. The supervision of the experiment at each location was reliant on different people and, in addition, there were staff changes during the course of the experiment that could possibly have had an influence on the accuracy of the sera and data collection. Furthermore, the data evaluation at Msogwaba was influenced by the low numbers of animals 
bled on certain dates, for example at Week 55 only $28 \%$ of the animals initially recruited for the study were presented at the dip tank. It is also possible that cattle could accidentally have been vaccinated during the routine bi-annual vaccination campaign, explaining why the titres against the SAT 1 and 2 antigens in ISA 206B vaccine formulation without saponin (formulation 8) at Msogwaba dip tank were positive at Week 55 (Fig. 2D and E).

Smitsaart and co-workers (2000) evaluated W/O FMD vaccine formulations containing saponin as immunostimulant in different cloven-hoofed domestic animal species. Cattle vaccinated with W/O-adjuvanted FMD vaccine with saponin at a payload of $9.7 \mu \mathrm{g}$ per dose developed significantly higher initial antibody titres than cattle vaccinated with a W/O vaccine at a payload of $38.8 \mu \mathrm{g}$ per dose without saponin (Smitsaart et al. 2000). The cattle vaccinated with $\mathrm{W} / \mathrm{O}$ vaccine with added saponin developed higher IgG1 and IgG2 responses than the vaccine without added saponin. In a follow-up trial ISA 206-based FMD vaccines consisting of monovalent O1 Campos (payloads of $5 \mu \mathrm{g}$ and $20 \mu \mathrm{g}$ per dose) were evaluated in the presence or absence of saponin. The enhancing effect of saponin was only apparent in cattle at low antigen payloads when compared to ISA 206-based vaccines lacking saponin (Smitsaart et al. 2004). Although high antigen payloads were not tested in our investigation, no obvious advantageous effect of saponin in the ISA 206B-adjuvanted vaccine was observed when compared to the ISA 206B vaccine without saponin when using low payloads. In this investigation 67\% of cattle were protected for 1 year after receiving a primary vaccination and boosted 8 weeks later with ISA 206B-adjuvanted FMD vaccine containing saponin. This is in contrast to a previous study in which only $40 \%$ of cattle were protected 1 year after receiving a single vaccination with a W/O/W-adjuvanted FMD vaccine containing a higher SAT antigen payload but no saponin (Hunter 1996). It is therefore necessary to investigate further the potential benefits of adding saponin to the oil-based vaccines using SAT antigens.

The results emanating from this study show that ISA 206B- and AS-adjuvanted vaccines may be equally suitable for use in South Africa, since both provided equal levels of protection against challenge. However, this study was based on a small number of animals, and it is possible that the ISA-based vaccines would provide better protection, as high antibody levels have been shown to correlate with protection (Barnett, Statham, Vosloo \& Haydon 2003).
Owing to the extensive farming practices prevalent in the buffer zone in SA it is not always possible to access animals on a regular basis for vaccination and the longer-lasting ISA 206B-adjuvanted vaccine would therefore be preferable. Additionally, the antibody levels are more readily detectable, which is advantageous when serosurveillance is performed to monitor the efficacy of the vaccination campaign. However, further research is required to optimize the vaccines having an auto boost effect, which would eliminate the need for boosters. The effect of antigen payload must be investigated to determine whether an increased payload can lead to an increase in the duration of neutralizing antibody body levels in cattle following a single vaccination.

\section{ACKNOWLEDGEMENTS}

We thank the Department of Agriculture and the Red Meat Research and Development Trust in SA for financial assistance. Dr Stephane Ascarateil, Seppic, AirLiquide, Paris, France, supplied the sample Montanide ISA 206B, ISA 50V and IMS 1313 emulsions used in this study. Dr Ben du Plessis and personnel of the Mpumalanga Veterinary Services, Nelspruit, Mpumalanga assisted with communication to the local farmers of the Msogwaba and Daantjie dip tanks to participate in this project, and to allow their cattle to form part of this investigation. The late Mr Billy Phologane, Mr Jan Esterhuysen and Ms Karin Boshoff performed the virus neutralization tests and ELISAs. Drr Comfort Phiri and Alison Lubisi performed the animal work for the cattle potency tests. Mr Chris van Vuuren and personnel assisted with the cattle trials at Kaalplaas, Onderstepoort, and Ms Kerstin Malan formulated the vaccines used in the study. Ms Marie Smith and Nicolene Thiebaut of the ARC Biometry Unit carried out the statistical analysis used in this study. Dr Mary-Louise Penrith critically reviewed the manuscript. Without all their assistance, this paper would not be possible.

\section{REFERENCES}

AUCOUTURIER, J., DUPUIS, L. \& GANNE, V. 2001. Adjuvants designed for veterinary and human vaccines. Vaccine, 19: 2666-2672.

BAHNEMANN, H.G. \& MESQUITA, J.A. 1987. Oil-adjuvanted vaccine against foot-and-mouth disease. Bulletin Centro Panamericano Fiebre Altosa, 53:25-50.

BARNETT, P.V. \& CARABIN, H. 2002. A review of emergency foot-and-mouth disease (FMD) vaccines. Vaccine, 20:15051514. 
BARNETT, P.V., COX, S.J., AGGARWAL, N., GERBER, H. \& MCCULLOUGH, K.C. 2002. Further studies on the early protective responses of pigs following immunization with high potency foot-and-mouth disease vaccine. Vaccine, 20:31973208.

BARNETT, P.V. \& DOEL, T.R. 1992. Stability and potency studies of FMD vaccines prepared from antigens stored in the Pirbright bank: comparison between the oil and $\mathrm{Al}(\mathrm{OH})_{3}$ formulations. Report of the Research Group of the Standing Technical Committee of the European Commission for the Control of Foot-and-mouth Disease, Berne.

BARNETT, P.V., KEEL, P., REID, S., ARMSTRONG, R.M., STATHAM, R.J., VOYCE, C., AGGARWAL, N. \& COX, S.J. 2004. Evidence that high potency foot-and-mouth disease vaccine inhibits local virus replication and prevents the carrier state in sheep. Vaccine, 22:1221-1232.

BARNETT, P.V., PULLEN, L., WILLIAMS, L. \& DOEL, T.R. 1996. International bank for foot-and-mouth disease vaccine: assessment of Montanide ISA 25 and ISA 206, two commercially available oil adjuvants. Vaccine, 14:1187-1198.

BARNETT, P.V. \& STATHAM, R.J. 2002. Stratified and cryogenically stored (SACS) vaccines, a new concept in emergency foot-and-mouth disease vaccine formulation and storage. Vaccine, 20:2060-2064.

BARNETT, P.V., STATHAM, R.J., VOSLOO, W. \& HAYDON, D.T. 2003. Foot-and-mouth disease vaccine potency testing: determination and statistical validation of a model using a serological approach. Vaccine, 21:3240-3248.

BRÜCKNER, G.K., VOSLOO, W., DU PLESSIS, B.J.A., KLOECK, P.E.L.G., CONNOWAY, L., EKRON, M.D., WEAVER, D.B., DICKASON, C.J., SCHREUDER, F.J., MARAIS., T. \& MOGAJANE, E. 2002. Foot-and-mouth disease: the experience of South Africa. Revue Scientifique et Technique, 21:751-764.

BRÜCKNER, G.K., VOSLOO, W., CLOETE, M., DUNGU, B. \& DU PLESSIS, B.J. 2004. Foot-and-mouth disease control using vaccination: South African experience. Developmental Biology, 119:51-62.

CHILDERSTONE, A.J., CEDILLO-BARON, L., FOSTER-CUEVAS, M. \& PARKHOUSE, M.E. 1999. Demonstration of bovine $\mathrm{CD}^{+} \mathrm{T}$-cell responses to foot-and-mouth disease virus. Journal of General Virology, 80:663-669.

COTTRAL, G.E. 1972a. Foot-and-mouth disease virus neutralization test cross reactions. Bulletin Office International des Epizooties, 77:1239-1261.

COTTRAL, G.E. 1972b. Foot-and-mouth disease virus neutralization test cross reactions: a comparison of cattle and guinea pig serums. Proceedings of the $76^{\text {th }}$ Annual Meeting of the US Animal Health Association: 194-207.

COX, S.J., BARNETT, P.V., DANI, P. \& SALT, J.S. 1999. Emergency vaccination of sheep against foot-and-mouth disease: protection against disease and reduction in contact transmission. Vaccine, 17:1858-1868.

COX, J.C. \& COULTER, A.R. 1997. Adjuvants-a classification and review of their modes of action. Vaccine, 15:248-256.

COX, S.J., VOYCE, C., PARIDA, S., REID, S.M., HAMBLIN, P.A., PATON, D. \& BARNETT, P.V. 2005. Protection against direct-contact challenge following emergency FMD vaccination of cattle and the effect of virus secretion of the oropharynx. Vaccine, 23:1106-1113.

COX, S.J., VOYCE, C., PARIDA, S., REID, S.M., HAMBLIN, P.A., HUTCHINGS, D., PATON, D. \& BARNETT, P.V. 2006. Effect of emergency FMD vaccine payload on protection, sub-clinical infection and persistence following direct contact challenge of cattle. Vaccine, 24:3184-3190.
DE LEEUW, P.W., TIESSINK, J.W.A. \& VAN BEKKUM, J.G. 1979. The challenge of vaccinated pigs with foot-and-mouth disease virus. Zentralblatt für Veterinärmedizin, 26:98-109.

DORA, J.F.P., COELHO NUNES, J.C., GOULAR DE SILVEIRA, J.C., JORGENS, E.N., ROSENBERG, J.F. \& ASTUDILLO, V.M. 1984. Epidemic of foot-and-and-mouth disease in Bage, R.S., Brazil, 1980: Evaluation of two systems of vaccination. Bulletin Centro Panamericano Fiebre Altosa, 49-50:11-17.

EBLÉ, P.L., BOUMA, A., DE BRUIN, M.G.M., VAN HEMERTKLUITENBERG, F., VAN OIRSCHOT, J.T. \& DEKKER, A. 2004. Vaccination of pigs two weeks before infection significantly reduces transmission of foot-and-mouth disease virus. Vaccine, 22:1372-1378.

EBLÉ, P.L., DE BRUIN, M.G.M., BOUMA, A. VAN HEMERTKLUITENBERG, F. \& DEKKER, A. 2006. Comparison of immune responses after intra-typic heterologous and homologous vaccination against foot-and-mouth disease virus infection in pigs. Vaccine, 24:1274-1281.

EBLÉ, P.L., BOUMA, A., WEERDMEESTER, K., STEGEMAN, J.A., \& DEKKER, A. 2007. Serological and mucosal immune responses after vaccination and infection with FMDV in pigs. Vaccine, 25:1043-1054.

GOLDE, W.T., PACHECO, J.M., DUQUE, H., DOEL, T., PENFOLD, B., FERMAN, G.S., GREGG, D.R. \& RODRIQUEZ, L.L. 2005. Vaccination against foot-and-mouth disease confers complete protection in 7 days and partial protection in 4 days: Use in emergency outbreak response. Vaccine, 23: $5775-5782$

HAMBLIN, C., BARNETT, I.T. \& HEDGER, R.S.A. 1986. A new enzyme-linked immunosorbent assay (ELISA) for the detection of antibodies against foot-and-mouth disease virus. I. Development and method of ELISA. Journal of Immunological Methods, 93:115-121.

HUNTER, P. 1996. The performance of southern African territories serotypes of foot-and-mouth disease antigen in oil-adjuvanted vaccines. Revue Scientifique et Technique, 15:913922.

HUNTER, P. 1998. Vaccination as a means of control of footand-mouth disease in sub-Saharan Africa. Vaccine, 16:261264.

IYER, A.V., GHOSH, S., SINGH, S.V. \& DESHMUKH, R.A. 2001. Evaluation of three ready to formulate oil adjuvants for footand-mouth disease vaccine production. Vaccine, 19:10971105.

KITCHING, R.P., BARNETT, P.V. \& DONALDSON, A.I. 2000. Foot-and-mouth disease, in Manual of standards for diagnostic tests and vaccines, edited by OIE Biological Standards Committee. Paris: OIE

PATIL, P.K., BAYRY, J., RAMAKRISHNA, C., HUGAR, B., MISRA, L.D. \& NATARAJAN, C. 2002a. Immune responses of goats to foot-and-mouth disease quadrivalent vaccine: comparison of double-oil emulsion and aluminium hydroxide gel vaccines in eliciting immunity. Vaccine, 20:2781-2789.

PATIL, P.K., BAYRY, J., RAMAKRISHNA, C., HUGAR, B., MISRA, L.D., PRABHUDAS, K. \& NATARAJAN, C. 2002b. Immune responses of sheep to foot-and-mouth disease quadrivalent vaccine: rate of development of immunity and variations among other ruminants. Journal of Clinical Microbiology, 40:4367-4371.

PAYNE, R.W. (Ed). 2003. Genstat@ for Windows $\AA, 7^{\text {th }}$ ed. (Introduction). VSA International.

QUATTROCCHI, V., BIANCO, V., FONDEVILA, N., PAPPALARDO, S., SADIRA, A. \& ZAMORANO, P. 2004. Use of new adjuvants in an emergency vaccine against foot-and-mouth 
disease virus: evaluation of conferred immunity. Control of Infectious Animal Diseases by Vaccination, Developmental Biology, 119:481-497.

QUATTROCCHI, V., FONDEVILA, N., PAPPALARDO, S., SADIRA, A. \& ZAMORANO, P. 2006. Development of an adjuvanted vaccine with rapid delivery against foot-and-mouth disease virus (FMDV). The Third International Workshop on Vaccine Adjuvants and Glycoconjugates, Varadero, Cuba, April 16-20, 2006.

RWEYEMAMU, M.M., BOOTH, J.C., HEAD, M. \& PAY, T.W.F. 1978. Microneutralization tests for serological typing and subtyping of foot-and-mouth disease virus strains. Journal of Hygiene (London), 81:107-123.

SMITSAART, E., ESPONOZA, A.M., SANGUINETTI, R., FILIPPI, J., HAM, A. \& BELLINZONI, R. 2004. Addition of saponin to double oil emulsion FMD vaccines enhances specific antibody responses in cattle and pigs. Report on the European Commission for the control of foot-and-mouth disease. Session of the Research Group of the Technical Standing Committee, Food and Agriculture Organization of the United Nations, Chania, Greece, 11-15 October 2004: 344-351.

SMITSAART, E., MATTION, N., FILIPPI, J.L., ROBIOLO, B., PERIOLO, O., LA TORRE, J. \& BELLINZONI, R.C. 2000. Enhancement of the immune response induced by the inclusion of saponin in oil adjuvanted vaccines against foot-and- mouth disease. Session of the Research Group of the Standing Technical Committee of the European Commission for the Control of FMD. Borovets, Bulgaria (Appendix), 32:255-262.

SNEDECOR, G.W. \& COCHRAN, W.G. 1980. Statistical methods, $7^{\text {th }}$ ed. Ames: lowa State University Press.

STELLMANN, C. TERR, J., FAVRE, H., BRUN, A. \& FONTAINE, J. 1977. Comparison of foot-and-mouth disease vaccine potency in terms of the nature of the diluent. Archives of Virology, 54:61-74.

SUTMOLLER, P., BARTELING, S.S., OLASCOAGA, R.C. \& SUMPTION, K.J. 2003. Control and eradication of foot-andmouth disease. Virus Research, 91:10-144.

VAN BEKKUM, J.G., BOOL, P.H. \& VERMEULEN, C.J. 1967. Experience with the vaccination of pigs for the control of footand-mouth disease in the Netherlands. Tijdschrift voor Diergeneeskunde, 92:87-97.

VOSLOO, W., BASTOS, A.D.S., SANGARE, O., HARGREAVES, S.K. \& THOMSON, G.R. 2002a. Review of the status and control of foot-and-mouth disease in sub-Saharan Africa. Revue Scientifique et Technique, 21:437-449.

VOSLOO, W., BOSHOFF, K., DWARKA, R. \& BASTOS, A. $2002 \mathrm{~b}$. The possible role that buffalo played in the recent outbreaks of foot-and-mouth disease in South Africa. Annals of the New York Academy of Sciences, 969:187-190. 